\title{
O APOIO INTERNACIONAL À TRANSIÇÃO PARA A DEMOCRACIA NA AMÉRICA LATINA **
}

ALAN ANGELL

Esta exposição poderia ser muito breve caso os três caminhos mais eficazes para a consolidação da democracia fossem adotados.

A necessidade mais premente, é claro, é a de que se tomem medidas rápidas e eficazes para aliviar a dívida externa. Não é necessário enfatizar as conseqüências terríveis, para as economias $\mathrm{e}$ as sociedades latino-americanas, do esforço realizado no sentido de pagar os juros sobre as enormes dívidas acumuladas por governos passados numa época de imprudentes operações de tomada e oferta de empréstimos. Contudo, o alívio imediato é pouco provável, enquanto for do interesse dos poderes centrais e dos grandes bancos internacionais preservar o atual sistema ao invés de reformá-lo em profundidade.

\footnotetext{
*Tradução de Régis de Castro Andrade.

** Texto apresentado no ciclo de conferências sobre a América Latina e os Novos Desafios da Ordem Internacional, organizado pelo Centro de Estudos de Cultura Contemporânea (CEDEC), pelo Departamento de Ciência Política da USP e pela Fundação do Desenvolvimento Administrativo (FUNDAP) em São Paulo, novembro de 1989.
} 
Igualmente importante para as economias da América Latina é o livre acesso aos mercados do mundo desenvolvido, sem as medidas protecionistas atualmente existentes. Num discurso de 1986, o presidente Sanguinetti, do Uruguai, referiu-se a essa questão nos seguintes termos:

Ou o comércio internacional se abre ou todos nós teremos de nos resignar a viver sob um novo feudalismo. Os mais poderosos talvez se adaptem melhor, mas eles estarão condenados a viver num mundo agressivo e instável, cheio de violência. Os países menotes, como nós, serão condenados a uma vida mediana, tendendo definitivamente para a pobreza.

Em terceiro lugar, o papel do apoio internacional seria muito menos controvertido se fosse organizado através de agências genuinamente multilaterais, ao invés de depender em grande parte, como hoje em dia, de iniciativas bilaterais. $\mathrm{O}$ apoio internacional raramente é desinteressado. Os que prestam ajuda podem, por exemplo, buscar acesso aos mercados locais, obter apoio político futuro ou tentar desembaraçar-se de equipamentos obsoletos. Esses fatores são muito mais óbvios, e têm muito mais probabilidade de ocorrer quando o apoio é dado bilateralmente. Pode-se suspeitar, por exemplo, que pouco do que os Estados Unidos fazem hoje na América Latina fuja ao objetivo de ampliar a influência daquele país, quaisquer que sejam os motivos específicos para uma determinada política. E há boas razões históricas para tal suspeita.

Nenhuma dessas três vias tem forte probabilidade de ser adotada pelos países desenvolvidos, e os países da América Latina são muito fracos para impô-las sozinhos. Mas minha preocupação aqui não é examinar o que ocorreria num mundo melhor do que o atual; desejo, antes, verificar o que de fato ocorreu num certo número de países, tentar explicar a influência dos fatores internacionais em alguns casos e considerar a influência disso no complicado processo de consolidação democrática.

Dessa forma pretendo examinar (1) o apoio que tem sido prestado em termos políticos e morais, ademais da ajuda econômica, (2) o apoio dado a movimentos políticos e sociais no 
período de oposição aos governos autoritários, bem como o apoio dado aos governos na fase de transição e (3) até que ponto o apoio internacional visou não apenas estabelecer governos democráticos, mas também criar sociedades democráticas.

A discussão dessa questão é imensamente complicada e tentarei apenas esboçar alguns problemas. Para um enquadramento analítico inicial, farei as seguintes observações:

1 - No processo de consolidação da democracia, os fatores cruciais são internos, não externos. $O$ apoio internacional pode ajudar ou prejudicar o processo, mas não pode determinálo. Os atores políticos cruciais no processo de transição são nacionais: partidos políticos, empresários, trabalhadores, militares, a Igreja e os intelectuais, para mencionar apenas os atores óbvios.

2 - Tenho claro que muitos dos termos que uso neste trabalho requerem definição. Quais são os parâmetros da democracia? Quando termina a transição? Quando as forças antidemocráticas tornam-se incapazes de desestabilizar o sistema constitucional? É possível estabelecer a democracia nas condições econômicas prevalecentes hoje em países como o Brasil, a Argentina ou o Peru? Tocarei nessas questões no que segue; mas como cada uma poderia ser objeto de um trabalho inteiro, não poderei dar a elas um tratamento adequado. ${ }^{1}$

3 - Também é óbvio que o processo de transição encontra-se nos seus estágios iniciais num certo número de países. Mesmo no Peru, onde os militares devolveram o poder aos civis em 1980, um conjunto de circunstâncias - o terrorismo do Sendero Luminoso, a terrível situação econômica, a influência do narcotráfico e a arbitrariedade do presidente Garcia e de seu partido - torna muito frágil a democracia.

Tanto o Chile como o Brasil terão de realizar eleições presidenciais diretas, e embora as perspectivas sejam boas no Chile, permanece ali a incerteza ligada ao poder residual do general Pinochet, e além disso o modelo econômico ali implantado permanece muito vulnerável aos fatores internacionais cambiantes.

A domesticação do peronismo na Argentina auxilia, seguramente, o processo de democratização naquele país, mas a

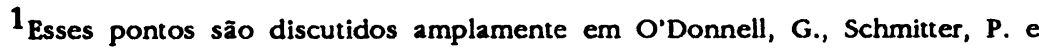
Whitehead, L., Transitions from Autboritarian Rule: Comparative Perspectives, Baltimore, 1988 e Moisés, J. A. e Alburquerque, J. A. (orgs.) Dilemas da Consolidação Democrática, São Paulo, 1989. 
questão dos direitos humanos ainda não foi resolvida e o colapso do Partido Radical não favorece o estabelecimento de um bipartidarismo estável. Pode-se argumentar que o processo avançou mais no Uruguai, apesar de que, curiosamente, a transição ali parece consistir mais num retorno ao velho sistema que uma renovação ou modernização do sistema. Ademais, a economia permanece muito vulnerável. No Paraguai, a transição mal começou.

4 - Não obstante, parece claro que os fatores internacionais jogaram o papel mais importante em alguns países que em outros. A esse respeito, argumentarei que (a) o país onde fatores internacionais mais pesaram, com influência positiva sobre o desenlace, foi o Chile; (b) fatores internacionais de natureza muito diversa tiveram considerável influência na Argentina, mas apenas num momento de crise real do regime, e tiveram pouca influência no processo de transição; (c) fatores internacionais tiveram pouca influência no Paraguai, especialmente porque afora certas ações recentes e não muito eficientes dos Estados Unidos, influências externas de qualquer tipo eram muito débeis naquele país; (d) os fatores internacionais também tiveram pouca influência no caso brasileiro, porque o regime militar deu mais liberdade à atividade política, e em particular ao processo eleitoral, que em outros países. Além disso, o Brasil é bem integrado aos sistemas econômico e político internacionais; (e) no caso do Uruguai, houve uma influência internacional modesta, proveniente do Brasil e da Argentina, e não de outros países.

5 - Gostaria igualmente de assinalar que por "fatores internacionais" já não se entende apenas a influência americana. A Comunidade Européia, o Japão e o Canadá são países que desempenharam papéis de crescente importância no processo de transição. De fato, no caso do Brasil, os Estados Unidos parecem ter tido um papel realmente sem importância. Segundo o exembaixador Langhorne Motley:

Os Estados Unidos não tiveram participação na abertura (...). Eu sempre defendi junto a Washington - e dessa vez fui ouvido - que a abertura foi feita no Brasil, e que o melhor para os Estados Unidos era ficar fora dela. Tudo o que fizemos foi aplaudir o processo. Não houve nenhuma agenda secreta de envolvimento americano. 
Não nos intrometemos na abertura porque interferir nela seria a coisa mais burra que poderíamos fazer, embora tenhamos insistido na garantia do direito de expressão aos grupos de oposição e na necessidade de negociar com todos os setores da sociedade, inclusive a Igreja. ${ }^{2}$

6 - Também é evidente que hoje em dia os fatores internacionais não se reduzem a governos estrangeiros. Hoje é necessário também verificar as atividades de grupos como as Igrejas, tanto a Católica como a Protestante, organizações não governamentais (ONGS), movimentos sindicais internacionais, grupos internacionais de direitos humanos, lobbies ecológicos internacionais e assim por diante. É clain que agências financeiras como o Banco Mundial e o Fundo Monetário Internacional podem ter um impacto considerável sobre o processo de transição; sua ação política no passado ficou óbvia nos casos de suas intervenções no Chile de Allende e na Nicarágua pós-rcvolucionária. Se hoje o Banco Mundial leva em conta o impacto ambiental dos projetos de financiamento, ou o efeito desses projetos na situação das mulheres, pode-se igualmente supor que faça avaliações comparáveis do impacto das condições dos empréstimos sobre a estabilidade política nos países receptores.

7 - À parte a atenção que se deve dar às políticas e aos atores internacionais, cabe considerar, de modo geral, o que pode chamar-se clima ideológico internacional prevalecente. Esse aspecto é bem resumido por Bolivar Lamounier:

(...) o esforço de construção institucional e a busca de uma fórmula de legitimidade não são processos confinados às fronteiras nacionais. Eles são fortemente influenciados pelos grandes modelos internacionais (por exemplo, pelo prestígio da democracia liberal ou do sindicalismo, em contraste com o descrédito do fascismo e de tudo o que, na cabeça dos atores relevantes, se associa a ele, como o corporativismo);

${ }^{2}$ Motley, L., "Letting off Steam", in Binnediyk, H. (org.) Authoritarian Regimes in Transition, Washington, 1987. 
pela opinião pública internacional, e em particular pelas grandes instituições transnacionais como a Igreja Católica, a imprensa, a comunidade acadêmica etc.; enfim, eles são evidentemente influenciados pela natureza das relações econômicas e políticas que o governo brasileiro é obrigado a manter e cultivar. ${ }^{3}$

\section{QUE FATORES TORNAM EFETIVO O APOIO INTERNACIONAL?}

Gostaria de sugerir alguns fatores que ajudam a entender por que o apoio internacional tem sido, por exemplo, relativamente importante no caso chileno e menos importante em outros casos.

1 - A importância das ligações internacionais dos atores políticos domésticos. $O$ exemplo que discutirei aqui é a estreita vinculação, desenvolvida pelos partidos políticos chilenos, com vários partidos irmãos da Europa.

2 - O grau de repúdio do regime nacional pela opinião pública internacional. Também desse ponto de vista, o caso do Chile sob Pinochet foi excepćional. Nenhum outro regime mereceu com tal intensidade o status de pária no contexto internacional. O governo militar no Brasil gozou de relações relativamente normais com a comunidade internacional. $O$ regime paraguaio foi em grande medida ignorado, embora não especialmente apreciado. Os militares argentinos, que podem ser considerados tão brutais como os chilenos, nunca foram tão inequivocamente condenados, em parte porque mantinham relações relativamente boas com a União Soviética, em parte porque toleravam o partido comunista no país e, em parte, finalmente, porque através da exportação de grãos, detinham um certo poder de barganha, que lhes garantia certo grau de proteção com respeito a pressões internacionais (tal como constatou o presidente Carter quando buscou o apoio argentino ao boicote aos cereais soviéticos).

3Lamounier, B., "Authoritarian Brazil Revisited", in Stepan, A. (ed.) Democratizing Brasil, Nova York, 1988, p. 53. 
3 - A latitude de ação de que gozava a oposição no interior do sistema político nacional. Aqui, a exceção é o Brasil, em que se realizaram eleições periódicas. Como escreveu Bolivar Lamounier:

(...) o processc brasileiro é caracterizado pelo seu caráter totalmente endógeno e pelo seu gradualismo. Mesmo em comparação com a Espanha, onde a redemocratização foi endógena (isto é, nenhuma derrota séria afetou a coesão e a credibilidade das Forças Armadas), o caso brasileiro é notável por sua duração (...) Essa é possivelmente a razão pela qual o calendário eleitoral desempenhou papel tão crucial, embora limitado (...) Iniciado em 1974, o processo eleitoral no Brasil foi na realidade um teste de forças e de legitimidade, e não um símbolo e a culminação de um pacto de transição já negociado sobre outra base pelos atores relevantes $(. .)^{4}$

No caso chileno tal atividade não foi possível e a política de oposição desenvolveu-se no exterior e não no Chile. Mesmo na Argentina, alguns atores políticos praticamente impedidos de operar no Chile - especialmente o movimento sindical gozavam de maior grau de liberdade. Além disso, para os exilados chilenos, foi mais fácil relacionar-se com a política dos países anfitriões; para os argentinos isso foi incerto, mais dificil, em razão do seu sistema político inusual.

4 - O tamanho do país também tem alguma influência. É bastante evidente que, fazendo-se abstração de outros fatores, é mais fácil influir na política de um país pequeno como o Chile, que num grande, como o Brasil. Mas é claro que não se pode fazer abstração de outros fatores, como o demonstram os casos de Noriega ou Stroessner.

5 - O papel da Igreja como ator no processo de negociação, que dispõe de consideráveis recursos e que opera com um certo grau de impunidade com respeito aos governos nacionais, também é importante. Desse ponto de vista, os casos

${ }^{4}$ Idem, pp. $69-70$ 
chileno e brasileiro são semelhantes; nos dois países a Igreja desempenhou um papel crucial na defesa das liberdades básicas, na proteção dos movimentos sociais e políticos, e enquanto conduto através do qual grandes somas de dinheiro neles ingressaram. Na Argentina, no Uruguai e no Paraguai não ocorreu esse envolvimento ativo da Igreja, o que sem dúvida aumentou as dificuldades da oposição nesses países.

\section{UM CASO BEM-SUCEDIDO: O CASO CHILENO}

No que segue, desejo analisar em maior detalhe o caso em que o apoio internacional desempenhou o papel mais significativo, embora, repito, em relação subordinada com respeito às forças políticas internas.

1 - A política de oposição no Chile, do golpe de 1973 até os movimentos de protesto de 1983 , foi conduzida no exterior, e não no Chile. ${ }^{5}$ Os exilados chilenos forjaram relações próximas com vários governos, com organizações não governamentais e com partidos políticos. Essas relações foram cruciais na criação de condições de sobrevivência da oposição, no financiamento da oposição - especialmente no plebiscito de 1988 -, na reformulação das idéias e atitudes dos partidos de oposição e no contundente isolamento internacional do regime de Pinochet, para o qual contribuíram. O número de exilados no Chile foi maior do que em outros países - pelo menos no que toca às elites políticas - e, dada a intensa condenação internacional do golpe chileno, os exilados foram calorosa e favoravelmente recebidos num grande número de países em todo o mundo. 6

2 - Em razão, parcialmente, do golpe do qual nasceu, o regime de Pinochet foi repudiado como nenhum outro regime latino-americano. Seus aliados foram a China, Israel e a África do Sul. Suas relações com os Estados Unidos nunca foram boas, e normalmente hostis, devido em parte ao assassinato de Orlando

5 Esta seção utiliza amplamente o estudo de caso de minha autoria para o seminário do RIIA. Esse estudo está baseado em entrevista com chilenos no exílio e no Chile.

${ }^{6}$ Sobre o exílio, ver Arrate, J., Exilio: Textos de Democracia y Esperanza, Santiago, 1987, e Angell, A. e Carstairs, S. "The Exile Question in Chilean Politics", Third World Qwarterly, janeiro, 1987. 
Letelier no centro de Washington em 1976, em parte à ação dos lobbies por direitos humanos nos Estados Unidos, com o apoio do Congresso, e em parte, finalmente, devido a que convinha aos Estados Unidos condenar o Chile para justificar sua política na América Central. ${ }^{7}$

3 - O apoio internacional à oposição chilena manifestou-se de diversas formas:

a) apoio ao movimento sindical e aos partidos políticos no exílio;

b) apoio às atividades da Igreja, que era a única instituição não governamental capaz de operar no Chile com um certo grau de liberdade;

c) apoio a vários institutos de pesquisa e centros acadêmicos que foram muito importantes para a sobrevivência dos partidos políticos e para a formulação de uma visão alternativa da realidade chilena com respeito à visão difundida pelo governo. Esses institutos de pesquisa desempenharam um papel vital na organização da campanha de oposição no plebiscito.

4 - O apoio internacional à oposição no plebiscito foi crucial por várias razões:

a) o apoio financeiro foi essencial para a campanha nacional de registro de eleitores, bem como para a criação de sistemas paralelos de computação destinados a minimizar a possibilidade de fraude governamental no dia do plebiscito;

b) a presença de mais de mil observadores estrangeiros foi útil também na redução da possibilidade de fraude e no estímulo que deu aos chilenos para que comparecessem às urnas;

c) a presença maciça da imprensa e da TV estrangeiras tornou o processo muito transparente;

${ }^{7}$ Muñoz, H. e Portales, C., Una Amistad Esquiva: Las Relaciones de EEUU y Chile, Santiago, 1987. 
d) a declaração dos Estados Unidos de que consideraria como atos de muita gravidade quaisquer tentativas de interferir no resultado do plebiscito foi importante porque encorajou a oposição e induziu o governo a agir com cautela.

Mas por que o Chile despertou muito mais preocupação do que outros países?

a) em parte, devido à identificação de grande parte $\mathrm{da}$ esquerda internacional com os objetivos do governo de Allende e à hostilidade generalizada contra $O$ regime de Pinochet, em conseqüência da brutalidade do golpe e da repressão que se seguiu;

b) em parte, devido às estreitas ligações dos exilados e seus partidos com os partidos dos países em que eles se encontravam;

c) e em parte porque o Chile tornou-se uma espécie de caso simbólico em que posicionamentos morais poderiam ser assumidos sem medo de represálias ou de conseqüências adversas para o comércio internacional ou para o investimento. É sempre mais conveniente assumir atitudes morais contra regimes de paises periféricos e relativamente pouco importantes do que contra países que têm certo poder de pressão internacional.

Eu não desejo sustentar aqui que ${ }^{\circ}$ apoio internacional recebido pelo Chile foi inteiramente benéfico. De fato, os pioblemas com que se defronta o Chile decorrem, de modo geral, de um tipo de ajuda oferecida por outros países que têm em mira impor um certo tipo de democracia ao beneficiar certos grupos e não outros. De maneira mais direta, verifica-se no Chile o perigo de que se introduzam divisões próprias da guerra fria numa sociedade em que essas divisões não constituem a questão política mais importante.

Como assinala Manuel Antonio Garretón: 
A influência internacional deve evitar dois tipos de ação. Primeiro, deve evitar a vinculação da luta contra o regime militar e o restabelecimento da democracia ao conflito Leste-Oeste. Segundo, complementarmente ao primeiro, evitar a divisão da oposição em setores democráticos e não democráticos, de maneira a produzir efeitos não apenas na esfera política, mas também nas organizações sociais, e especialmente nos sindicatos. ${ }^{8}$

\section{A DEBILIDADE DOS FATORES INTERNACIONAIS NO CASO BRASILEIRO}

Se o Chile é um exemplo de transição onde os fatores internacionais fazem parte crucial do processo, o mesmo não ocorre no caso brasileiro, onde o impacto do apoio internacional foi muito limitado. Por que isso?

Em primeiro lugar, diferentemente do sistema partidário chileno, os partidos brasileiros tinham relativamente poucas ligações internacionais que pudessem ser invocadas para as demandas de apoio. No Brasil não existe um Partido Democrata Cristão comparável ao chileno; e foi esse partido, sobretudo, que carreou para o Chile um enorme (em termos chilenos) apoio financeiro, político e de outras naturezas, proveniente dos poderosos partidos democrata-cristãos europeus e da Democracia Cristã Internacional. Os partidos brasileiros normalmente não buscaram apoio material ou ideológico no exterior. Além dos partidos comunistas, os únicos que têm ligações oficiais são o PDT, que possui status de partido consultivo na Internacional Socialista e o PFL que, desde 1985, tem sido membro observador na Internacional Liberal. As fundações partidárias alemãs não têm sido tão ativas em estabelecer ligações partidárias no Brasil quanto em outros países da região.

Em segundo lugar, embora houvesse exilados e embora alguns deles tenham alcançado certo grau de proeminência política no exterior, como Brizola em Portugal, e em suas ligações com a Internacional Socialista, esses foram casos excepcionais e

${ }^{8}$ Garretón, M. A. Transición bacia la Democracia en Cbile y Influencia Extema, Documento de trabajo $n^{2}$ 282, FLACSO, Santiago, 1988, p. 27. 
não podem ser comparados com os exilados chilenos. Diferentemente do que se passou em qualquer outro regime militar na América Latina, no Brasil ocorriam eleições periódicas que mantinham os políticos, pelo menos parcialmente, envolvidos na vida política nacional. Os partidos, cujo funcionamento era permitido, constituíam-se em estranhos artefatos engendrados pelo sistema militar e não possuíam afinidades óbvias com os partidos da Europa. Talvez em 1985 tenha ocorrido alguma mudança; O PT tem ligações com alguns partidos italianos, embora ainda em escala relativamente pequena.

Em terceiro lugar, houve pouco interesse por parte da comunidade internacional no processo brasileiro de transição, que foi longo e complicado se comparado às transições chilena e filipina. O lobby dos direitos humanos no Brasil foi pouco ativo, a cobertura na imprensa internacional foi pequena e os grupos políticos e sindicais na Europa preocuparam-se pouco.

Talvez esses grupos sentissem que, embora pudessem influenciar a política de sociedades menores tais como o Chile ou outros países da América Central, isso não era possível no Brasil dada a sua magnitude.

Em quarto lugar, os movimentos populares no Brasil eram frouxamente organizados e houve relativamente poucos protestos sociais capazes de despertar o interesse internacional. De fato, Scott Mainwaring argumenta que "a debilidade dos movimentos populares, mais do que sua força, foi um fator importante para o surgimento da certeza dentro do regime de que ele poderia liberalizar-se sem efeitos adversos", embora ele complete dizendo que "com o correr do tempo a liberalização abriu mais espaço para os movimentos populares, e este espaço foi utilizado pelos movimentos para a inclusão de novos pontos na agenda política (...)".9

Em quinto lugar, em contraste com a população chilena, altamente politizada, no Brasil parece existir um ceticismo e uma apatia política bem maiores. Mainwaring cita uma pesquisa mostrando que em 1985, imediatamente antes das eleições "apenas dois dos partidos apresentavam uma taxa de identificação de mais de $35 \%$. Apenas 52 de 690 pessoas foram capazes de identificar o significado político de 'direita'. Quando

9Mainwaring, S., "Grassroots, Popular Movements and the Struggle for Democracy", in Stepan, A., op. cit. p. 196. 
se perguntou se as pessoas sabiam como escolher os candidatos, $60 \%$ responderam que não e apenas $17 \%$ que sim. Esta falta de consciência política permeia toda a estrutura social e é especialmente marcada entre os pobres". ${ }^{10}$ Esse é um contexto pouco propício para que as ligações políticas internacionais tenham grande impacto.

Em sexto lugar, diferentemente dos militares no Chile ou na Argentina, os militares brasileiros nunca estiveram isolados na arena política internacional. Mas ao mesmo tempo eles tornaram-se mais independentes de seus aliados próximos, os Estados Unidos, e menos sensíveis às pressões americanas. A política externa brasileira tornou-se mais independente em regiões como a África, o Oriente Médio e a América Central, distanciando-se cada vez mais dos Estados Unidos como conseqüência da pouca ajuda deles recebida em questões cruciais como a dívida externa. Também houve o envolvimento dos militares na criação da indústria da informática e o forte apoio dos militares para a política de resistência às pressões americanas para a alteração da Lei de Informática de 1984. Entre as instituições dos regimes autoritários, a instituição militar é a mais dificilmente influenciável por forças externas. O apoio internacional pode ajudar na mobilização das posições, mas as pressões para mudar um regime militar como o brasileiro devem provir dos atores domésticos e não dos internacionais.

A única exceção a esse padrão geral de ausência de envolvimento internacional foi o da Igreja, c a Igreja foi instrumento da criação e apoio a movimentos sociais necessários para a democratização da sociedade e do governo. A Igreja brasileira recebeu muito mais apoio e atenção que os partidos políticos brasileiros. Entre 1962 e 1977, o Brasil era o maior beneficiário da ajuda financeira das Igrejas alemãs, recebendo 94 milhões de marcos, o que significa mais do dobro recebido pelo Chile (a maior parte dos recursos veio das Igrejas protestantes alemãs e não dos grupos católicos). A atividade da Igreja no campo dos direitos humanos também foi fundamental para a sobrevivência dos grupos que nele militavam e para atrair a atenção a esse aspecto durante os longos anos de governo militar.

${ }^{10}$ Idem, pp. $183-4$. 
Não obstante, essa comparação com o Chile mostra, no geral, a influência internacional relativamente pequena na transição brasileira.

\section{O QUE ACONTECE QUANDO A OPOSIÇÃO SE TORNA GOVERNO?}

Concentrei-me até agora no papel do apoio internacional no processo de transição, especialmente no período em que os militares deixam o governo e passam-no a civis. $O$ apoio internacional nesse período foi principalmente político e direcionado às forças democráticas de oposição. Mas o que acontece quando esses movimentos se tornam governo? Qual deveria ser, nesse caso, o papel do apoio internacional?

Um dos pontos de partida é argumentar que o apoio nesse período deve ser econômico e geral, e não político e específico. Isso me remeteria ao meu argumento inicial de que as medidas mais efetivas seriam, de longe, o alívio da dívida externa e a remoção de barreiras protecionistas. Mas assumindo uma visão pessimista de que essas medidas não ocorram, pelo menos a curto prazo, que outro tipo de apoio poderia ser dispensado pela comunidade internacional para ajudar a consolidar a democracia?

Qualquer que seja a ajuda, deve evitar a interferência política aberta. Tais interferências na política doméstica correm sempre o risco de serem contraproducentes, de produzirem reações nacionalistas, e de prejudicarem os grupos que se quer ajudar: a história do envolvimento dos Estados Unidos na América Latina está repleta de exemplos desse tipo de efeitos, e isto reforça $o$ argumento de que no futuro a ajuda deva ser multilateral e não bilateral. Não há um conceito correto de democracia a ser imposto aos países latino-americanos pelos poderes metropolitanos. Mas falarei sobre isto mais adiante.

Um grupo de importância crucial na consolidação da democracia é o empresariado. Um elemento vital desse processo é induzir tal grupo dominante a restringir seu lobby a limites legítimos e a romper todos os seus vínculos com a direita não democrática. Um exemplo muito expressivo disso na Europa foi a 
atração que a Comunidade Econômica Européia exerceu sobre o empresariado espanhol, português e, mais recentemente, sobre o turco, dado que somerite países democráticos poderiam beneficiar-se plenamente da associação à Comunidade. Há equivalentes funcionais na América Latina?

O tratado Brasil-Argentina de 1988, o tratado ItáliaArgentina de 1987 e o tratado Espanha-Argentina de 1988 podem constituir exemplos desses equivalentes. A filosofia básica desses tratados é a combinação da expansão do comércio, da modernização econômica e do apoio à consolidação da democracia. $O$ tratado Brasil-Argentina visa criar num prazo de dez anos uma área de livre comércio, seguindo-se inicialmente um mercado comum concebido segundo o modelo da CEE em sua configuração de pós-1992. Evidentemente há enormes dificuldades no processo; entre elas não são despreziveis o desenvolvimento maior da indústria de bens de capital no Brasil e a lista relativamente pequena de produtos argentinos que foram incluídos ro acordo. Mas quaisquer medidas que aumentem o comércio e a cooperação ajudarão a reduzir animosidades tradicionais, a encorajar grupos empresariais, a fortalecer seu compromisso com o processo democrático e a reduzir as tensões políticas capazes de permitir o envolvimento político dos militares. ${ }^{11}$

$O$ tratado Argentina-Itália é ainda mais explicitamente ligado ao objetivo da consolidação da democracia na Argentina; com efeito, sua própria vigência depende da continuidade do experimento democrático naquele país. $O$ principal objetivo do tratado é elaborar um novo modelo de relações Norte-Sul baseadas em formas inovadoras de colaboração, numa asssociação para o desenvolvimento. Prevê-se a colaboração tanto no plano científico-cultural como no plano econômico. Deve-se dar preferência a joint ventures envolvendo pequenas e médias empresas. Espera-se que os empresários argentinos beneficiem-se do contato com o modelo italiano de desenvolvimento das pequenas $e$ médias empresas, adquiram novas tecnologias e tenham acesso a novos mercados; quanto aos empresários italianos, espera-se que se beneficiem da internacionalização dos seus negócios.

O tratado entre a Argentina e a Espanha acompanha de perto o tratado assinado com a Itália. Resta ver o que esses trata-

11 Esta seção utiliza o estudo de caso sobre a Argentina por Giorgio Alberti, apresentado em Seminário do RIIA. 
dos permitem obter. Eles podem, quanto ao principal, permanecer no plano das declarações de intenções, sem chegar a fomentar conquistas específicas. As expectativas não devem ser demasiado otimistas: a médio prazo, pelo menos, sua contribuição ao desenvolvimento econômico na Argentina e no Brasil será marginal. Mas idéias podem ganhar força e produzir resultados, mesmo quando há muitos obstáculos à sua implementação; e esses tratados de cooperação constituem um sinal positivo de um desejo de criar instituições capazes de contribuir para a estabilidade democrática.

De que maneira a influência internacional pode incidir sobre os militares, que são outro ator crucial nos processos políticos da América Latina? É difícil ver como isso pode ser feito no caso de Forças Armadas profissionais como as do Brasil e do Chile, que produzem partes substanciais do seu armamento ou que podem comprar o que desejam no mercado internacional sem serem incomodados pelos Estados Unidos. Ademais, em a mbos os casos, ou bem os militares possuem considerável poder político, como no Brasil, ou bem continuarão a deter tal poder após a transferência do governo aos civis, como no Chile. Talvez aqui os fatores de mudança não serão diretos, mas indiretos: entre eles, mencione-se o rápido processo de détente e as espantosas mudanças que estão ocorrendo na União Soviética e na Europa Oriental.

A retórica anticomunista do Estado de Segurança Nacional hoje soa como uma doutrina tão anacrônica como fascista; e na ausência de ameaças guerrilheiras de monta - a exceção aqui, obviamente, é o Peru - a motivação para intervir será menor. As mudanças nas esquerdas latino-americanas - que hoje enfatizam seu compromisso com a democracia e não com a revolução, e que rejeitam a violência em favor do processo eleitoral - devem igualmente contribuir para o fortalecimento dos sistemas democráticos e constitucionais e para o debilitamento dos motivos das intervenções militares. Em todo o caso, se os Estados Unidos são incapazes de controlar mesmo os militares de El Salvador, é provável que tenham muito pouca influência sobre os militares das maiores potências do Cone Sul. 


\section{CONCLUSÕES}

Gostaria de concluir com a discussão de duas importantes áreas em que o apoio internacional poderia continuar sendo efetivo. A primeira é a área dos direitos humanos. Mais uma vez convém realçar o papel subsidiário dos grupos internacionais: cada país deve decidir como institucionalizar os direitos dos seus cidadãos. Mas a coisa é mais complicada. Quando os direitos humanos são desrespeitados, a comunidade internacional tem o dever de chamar a atenção para os abusos e tentar reverter a situação. Talvez o apoio a políticas de direitos humanos em democracias emergentes seja uma das maneiras mais efetivas de fornecer apoio internacional à democracia na América Latina. Muitas das questões básicas no campo dos direitos humanos são diretamente relevantes para o sucesso dos regimes democráticos. A assim chamada "primeira geração" dos direitos humanos, envolvendo as liberdades civis e políticas, ajuda a reforçar a estrutura política na qual a política democrática se desenvolve. A "segunda geração" dos direitos humanos, que envolve os direitos sociais e econômicos, fornece os meios para o enfrentamento das dificuldades do desenvolvimento econômico. A "terceira geração", que se refere aos direitos dos grupos e comunidades, é claramente relevante, em países como o Brasil, por exemplo, no que diz respeito à proteção dos povos ameríndios. Há risco de paternalismo nessa área, e riscos de causar prejuizos em conseqüência de intervenções sem conhecimento real dos problemas, mesmo que essas intervenções sejam bem-intencionadas. Não obstante, há uma aceitação muito maior da legitimidade do envolvimento da comunidade internacional no campo dos direitos humanos do que no campo da promoção da democracia.

Gostaria de encerrar com uma nota de cautela. Tanto os advogados da democracia no plano internacional como os povos que vivem sob regimes democráticos recentes podem ter expectativas excessivas com respeito a democracia. Talvez seja melhor encarar a democracia como o regime de governo menos mau, ao invés de concebê-lo como uma fórmula para resolver enormes problemas com rapidez e eficiência. Amiúde, aqueles que defendem a democracia do exterior idealizam seus próprios sistemas, ou ignoram os inúmeros defeitos que os sistemas americano ou britânico apresentam aos olhos de um observador crítico. Ora, é muito mais difícil construir sistemas democráticos 
viáveis depois de anos de autoritarismo e em meio a uma crise econômica. Um dos maiores problemas com que se defrontam as democracias recentes é a demanda social reprimida, provinda de setores que foram excluídos dos beneficios do desenvolvimento.

A criação de meios de acomodar essas demandas sem debilitar as frágeis economias da América Latina requer imaginação, paciência e comedimento. De qualquer maneira, essas demandas têm mais probabilidades de ser atendidas em sistemas democráticos do que em sistemas autoritários. A comunidade internacional deve esforçar-se para criar as condições em que os países possam vir a elaborar seu próprio futuro, pois um continente latino-americano estável e democrático é do interesse de todos nós, e não apenas das nações latino-americanas.

Nota do autor. Este artigo está baseado nos estudos de caso apresentados no Seminário dirigido por Lawrence Whitehead no Royal Institute of International Affairs (RIIA), em Londres, e particularmente no estudo de caso sobre o Brasil, de autoria de Andrew Hurrell, do Nuffield College, Oxford.

ALAN ANGELL foi diretor do Latin American Center e é fellow do Saint Antony's College, Oxford, Inglaterra. 